\title{
Reinforcement of Quaternary Ammonium Modified Silica (QAMS) with Magnetite and its Application by Solid Phase Adsorption (SPA) to Adsorb Chromate Ions
}

\author{
Ngatijo Ngatijo ${ }^{a, 1, *}$, Restina Bemis ${ }^{a, 2}$, Abdul Aziz ${ }^{b, 3, *}$, Rahmat Basuki ${ }^{c, 4}$ \\ ${ }^{\text {a }}$ Department of Chemistry, Universitas Jambi, Jambi, Indonesia \\ ${ }^{\mathrm{b}}$ Master of Chemistry Program, Department of Chemistry, Institut Teknologi Sepuluh Nopember, Surabaya, Indonesia \\ c Department of Chemistry, Universitas Pertahanan, Bogor, Indonesia
}

* Corresponding author: (1,*) tij052@yahoo.co.id; (2) bemisrestina@gmail.com; (3) azizgb@gmail.com; (4)rhmtbsq@gmail.com

https://doi.org/10.14710/jksa.23.10.333-337

Article Info

Article history:

Received: $23^{\text {rd }}$ June 2020 Revised: $28^{\text {th }}$ September 2020 Accepted: $10^{\text {th }}$ October 2020 Online: $31^{\text {st }}$ October 2020

Keywords:

QAMS-Magnetite; Solid Phase Adsorption (SPA); chromate ions

\begin{abstract}
Chromium (VI) in the form of chromate anions that have toxic properties needs to be overcome. This study aims to reinforce cationic sorbent quaternary aminemodified silica with magnetite $\left(\mathrm{QAMS}-\mathrm{Fe}_{3} \mathrm{O}_{4}\right.$ ) to adsorb chromate ions. QAMS prepared by reflux methylation ammine modified silica (AMS) obtained from destruction silicate from rice husk ash followed by the addition of 3-APTMS. Characterization QAMS- $\mathrm{Fe}_{3} \mathrm{O}_{4}$ by FT-IR showed successfully of methylation process indicated by disappearing absorbance at $1388 \mathrm{~cm}^{-1}$, and emerging absorbance at $2939 \mathrm{~cm}^{-1}$ in QAMS and QAMS- $\mathrm{Fe}_{3} \mathrm{O}_{4}$ indicated a transformation of $\mathrm{N}-\mathrm{H}$ from $-\mathrm{NH}_{2}$ group to $\left[-\mathrm{N}^{+}\left(\mathrm{CH}_{3}\right)_{3}\right]$. XRD analysis denotes $2 \theta=30.15^{\circ}, 35.53^{\circ}$, $43.12^{\circ}, 57.22^{\circ}$, and $62.90^{\circ}$ (JCPDS No. 00-033-0664) fathomed as a characteristic peak of magnetite. SEM-EDX reveals the homogenous topological spherical form with an average particle size $0.006 \mu \mathrm{m}$ that is dominated by Si element $(52.81 \%)$ with magnetic moment value $=34.1 \mathrm{emu} / \mathrm{g}$. The stability test shows that this material stable in an acid condition. The adsorption of chromate ions was conducted by the SPA method. Optimal $\mathrm{pH}$ obtained by $\mathrm{pH}$ range 4-7 with more than $90 \%$ adsorbed chromate ions. Variation of increasing series flow rate from 0.05 to $1.5 \mathrm{~mL} \mathrm{~min}^{-1}$ resulted in decreased adsorbed chromate ions. The use of SPA methods offered simpler and easier handling than the batch method without overriding the adsorption process effectiveness.
\end{abstract}

\section{Introduction}

Gold mining activities harm the environment [1]. The gold mining process potentially causes environmental pollution because it causes turbidity and heavy metal pollution in river water used as a source of drinking water by society. One of the dangerous heavy metals is $\mathrm{Cr}$ metal [2, 3], chromium metal can be generated from chromium taken from the earth and the mining machines. Chromium ion in the form of $\mathrm{Cr}$ (III) ion and $\mathrm{Cr}(\mathrm{VI})$ ion is a chromium form widely found in the environment. The hexavalent $(\mathrm{Cr}(\mathrm{VI}))$ form receives more attention due to its toxic nature $[4,5]$. Chromium (IV) is known to have 100 times more toxic than chromium (III) for both acute and chronic exposures because of its high water solubility and mobility, as well as easy reduction [6].

One effective way to overcome $\mathrm{Cr}$ metal pollution is by the adsorption method [7, 8]. Potential material used as an adsorbent is silica gel (SG) from rice husk ash (RHA). Silica gel from RHA is obtained from the burning process of rice husk. SG from RHA is more superior to quartz because it has high crystallinity and stability [9]. However, the use of SG from RHA as an adsorbent has a weakness: the low capacity caused by the low acidity of $\mathrm{Si}-\mathrm{OH}$ groups [10]. Modification of silica by functionalization with a quaternary ammonium group to Quaternary Ammonium Modified Silica (QAMS) with a quaternary group $\left(-\mathrm{N}^{+}\left(\left(\mathrm{CH}_{3}\right)_{3}\right)\right.$ has the advantage that protonation will not occur; thus remains positively 
charged and persists in absorbing chromate anions [11, 12]. However, this material was challenging to re-collect after the adsorption process [13].

Magnetite $\left(\mathrm{Fe}_{3} \mathrm{O}_{4}\right)$ is one of the materials with various potential applications, including in magnetic recording technology, pigments, catalysis, photocatalysis, medical use, and environmental improvement [14]. Previous studies reported that magnetite modification of silica could increase the surface area of silica $[13,15]$. Also, magnetic materials such as magnetite $\left(\mathrm{Fe}_{3} \mathrm{O}_{4}\right)$ and maghemite $\left(\gamma-\mathrm{Fe}_{2} \mathrm{O}_{3}\right)$ have been reported to be incorporated into silica, i.e., silicaencapsulated particles, to rapidly separate the silica from aqueous environments after adsorption [16]. Coating $\mathrm{Fe}_{3} \mathrm{O}_{4}$ by silica also prevented the magnetite from aggregation and oxidation [17, 18, 19] and exhibited excellent stability in an acidic environment compared with the uncoated ones $[14,20]$. However, few authors have reported the preparation of QAMS coated magnetic materials and their application to remove pollutants [16, 20]. Nuryono et al. [21] reported that magnetite coating with mercapto-modified silica as an adsorbent has more effective interaction with metals with high chemical stability and easy to separate after the adsorption/desorption process.

The adsorption process was usually carried out using a batch method [22]. However, in recent years, a new adsorption method has been developed, which can be an option in the adsorption process; it was called the Solid Phase Adsorption (SPA) method. SPA is an adsorption method that uses columns as adsorption media [23]. This method was claimed more efficiently because it can minimize the analyte, regenerate the adsorbent, and be used repeatedly for the same analysis, easy preparation, and high selectivity [24]. Liu et al. [25] reported that adsorbent from polymer resin to adsorb Cr(III) using SPA had a high selectivity, good stability, and high adsorption capacity.

From the literature above, magnetite $\left(\mathrm{Fe}_{3} \mathrm{O}_{4}\right)$ seems a suitable candidate to modify QAMS to increase QAMS handling. This work objective was to reinforce the QAMS handling after the adsorption/desorption process by maintaining the magnetic moment of magnetite, $\mathrm{Fe}_{3} \mathrm{O}_{4}$, as modifier QAMS. The magnetic moment preservation of QAMS- $\mathrm{Fe}_{3} \mathrm{O}_{4}$ was conducted by synthesis $\mathrm{Fe}_{3} \mathrm{O}_{4}$ first and then coated with QAMS. The obtained material $\left(\mathrm{QAMS}-\mathrm{Fe}_{3} \mathrm{O}_{4}\right.$ ) was then applied to adsorb chromate $(\mathrm{Cr}(\mathrm{VI}))$ anion by using the Solid Phase Adsorption (SPA) method. Characterization of synthesized material $\left(\mathrm{QAMS}-\mathrm{Fe}_{3} \mathrm{O}_{4}\right.$ ) and adsorption studies of $\mathrm{Cr}(\mathrm{IV})$ onto QAMS- $\mathrm{Fe}_{3} \mathrm{O}_{4}$ with SPA will further discussed in this paper.

\section{Methodology}

\subsection{Materials}

Rice husk to produce rice husk ash (RHA) and analytical grade reagent, i.e., $\mathrm{HCl} 37 \%$ (E-Merck), $\mathrm{HNO}_{3}$ $68 \%$ (E. Merck), $\mathrm{NaOH}$ (E-Merck), 3Aminopropyltrimethoxysilane (3-APTMS, SigmaAldrich), $\mathrm{FeSO}_{4} \cdot 7 \mathrm{H}_{2} \mathrm{O}$ (E-Merck), $\mathrm{FeCl}_{3} \cdot 6 \mathrm{H}_{2} \mathrm{O}$ (E-Merck),
$\mathrm{CHCl}_{3}$ (E-Merck), $\mathrm{NH}_{4} \mathrm{OH} 24 \%$ (E-Merck), $\mathrm{CH}_{3} \mathrm{I}$ (SigmaAldrich), $\mathrm{K}_{2} \mathrm{CrO}_{4}$ (E-Merck), ethanol 60\% (E-Merck), and Dimethylformamide (DMF, Sigma-Aldrich).

\subsection{Instrumentations}

Supporting instrumentation was a set of standard glass tools (Erlenmeyer flask, volume pipette, beaker glass, and so forth), oven, furnace, analytical balance, desiccator, plastic tube, centrifuge, shaker, magnetism, $\mathrm{pH}$ meter, and reflux. Elemental analysis performed by Flame Atomic Absorption Spectroscopy (FAAS, Shimadzu AA6650) with Air-Acetylene flame gas, wavelength $357.9 \mathrm{~nm}$. Crystallinity analysis conducted by X-Ray Diffraction using Shimadzu X-ray diffraction (XRD) and using $\mathrm{CuK} \alpha$ radiation $(\lambda=1.5406 \AA$ ) operated at $40 \mathrm{kV}$ and $30 \mathrm{~mA}$ with the step size of $0.02^{\circ}$. Fourier Transform Infrared (FTIR, Shimadzu IR Prestige 21) analyzed the functional group of materials in the $\mathrm{KBr}$ pallet that scans the region between 4000 and $400 \mathrm{~cm}^{-1}$ with $4 \mathrm{~cm}^{-1}$ resolution. The morphology and the elemental composition of material performed by Scanning Electron Microscope-Energy Dispersive X-Ray (SEM-EDX, JEOL SSM-6510 LA) operating at an accelerating voltage of $15.00 \mathrm{kV}$ through an aliquot of a dilute particle suspension was allowed to air dry on glass slides and then were coated with evaporated carbon. Magnetization was recorded as a function of field $(-1.0$ to $+1.0 \mathrm{~T})$ at 297.2 K by Vibrating Sample Magnetometer (VSM, OXFORD VSM1.2H).

\subsection{Destruction of silicic acid from RHA}

Rice husk was furnace at $700{ }^{\circ} \mathrm{C}$ to produce RHA. The mixture of $100 \mathrm{~g}$ RHA, $80 \mathrm{~g}$ of $\mathrm{NaOH}$ crystals, and $500 \mathrm{~mL}$ of distilled water was stirred and boiled for 2 hours and then filtered after it was cooled. The $200 \mathrm{~mL}$ of its filtrate was mixed with $15 \mathrm{~mL}$ of 3-APTMS, and drop by drop gently of $2 \mathrm{M} \mathrm{HCl}$ to reach $\mathrm{pH}$ nine until formed sol. The sol was then aged for $3 \times 24 \mathrm{~h}$ to form a gel (Ammine Modified Silica, AMS) was formed. AMS was washed until the $\mathrm{pH}$ was neutral, filtered, and dried at $70{ }^{\circ} \mathrm{C}$ to generate dry $\mathrm{AMS}, \equiv \mathrm{Si}\left(\mathrm{CH}_{2}\right)_{3} \mathrm{NH}_{2}$.

\subsection{Methylation reaction to form QAMS from AMS}

Methylation reaction was performed by the procedure proposed by de Camposet al. [26]. The mixture of $12 \mathrm{~g}$ AMS, $20 \mathrm{~mL}$ DMF and $10 \mathrm{~mL}$ methyl iodide in 250 $\mathrm{mL}$ volume 3 neck flask was refluxed for six $\mathrm{h}$ at $70^{\circ} \mathrm{C}$ while a periodically dropwise of methyl iodide added in a dark room. The solid products were filtered and washed with water, then with a $2 \%$ sodium bicarbonate solution and again with water. The materials were dried under a vacuum at $50{ }^{\circ} \mathrm{C}$ for six hours. The methylation reactions were repeated two times by replacing AMS with the previous methylated product to generated QAMS, $\equiv \mathrm{Si}\left(\mathrm{CH}_{2}\right)_{3} \mathrm{~N}^{+}\left(\mathrm{CH}_{3}\right)_{3} \mathrm{I}^{-}$.

\subsection{Synthesis of Magnetite $\left(\mathrm{Fe}_{3} \mathrm{O}_{4}\right)$}

Magnetite synthesis was carried out based on Yang et al. [27] through the co-precipitation method by dissolving $1.05 \mathrm{~g} \mathrm{FeSO}_{4} \cdot 7 \mathrm{H}_{2} \mathrm{O}$ and $1.525 \mathrm{~g} \mathrm{FeCl}_{3} \cdot 6 \mathrm{H}_{2} \mathrm{O}$ into $25 \mathrm{~mL}$ of distilled water and heated to $90{ }^{\circ} \mathrm{C}$. $\mathrm{NH}_{4} \mathrm{OH} 25 \%$ was added to that homogenous mixture until $\mathrm{pH} 11$, and 
the mixture was stirred at $90{ }^{\circ} \mathrm{C}$ for 30 min as magnetic fluids. After aged $24 \mathrm{~h}$, the resulted black sediment was separated from the solution, washed until neutral $\mathrm{pH}$, and dried to generate magnetite, $\mathrm{Fe}_{3} \mathrm{O}_{4}$.

\subsection{Coating $\mathrm{Fe}_{3} \mathrm{O}_{4}$ with $\mathrm{QAMS}$}

Following Yang et al. [27] method with some modifications, the $\mathrm{Fe}_{3} \mathrm{O}_{4}$ with QAMS was carried out through the sol-gel approach in a basic ethanol/water mixture at $30{ }^{\circ} \mathrm{C}$ by using magnetic fluids as seeds. The method begins with the synthesis of $\mathrm{Fe}_{3} \mathrm{O}_{4}$ with the same recipe. After the magnetic fluid is formed and cooled to room temperature, under continuous mechanical stirring, a homogenous neutral suspension of $0.2 \mathrm{~g}$ of QAMS in $40 \mathrm{~mL}$ ethanol $60 \%$ was dropwise added to this dispersion. After stirring for $12 \mathrm{~h}$, the obtained product was collected by an external magnetic field and washed with ethanol three times. The dry solid (QMAS- $\mathrm{Fe}_{3} \mathrm{O}_{4}$ ) was then analyzed by the FT-IR, XRD, SEM-EDX, and VSM instrument.

\subsection{Stability Test of QAMS}

Ten mg of QMAS- $\mathrm{Fe}_{3} \mathrm{O}_{4}$ was inserted into a $25 \mathrm{ml} \mathrm{pH}$ solution with a variation of $\mathrm{pH} 1,2,3,4,5,6,7,8,9$, and 10. The solution was stirred for $15 \mathrm{~min}$. The remaining solids were filtered, dried, and weighed.

\subsection{Chromate Anions Adsorption by SPA}

A hundred mg of QAMS- $\mathrm{Fe}_{3} \mathrm{O}_{4}$ was inserted into the column, and then $10 \mathrm{~mL}$ of $10 \mathrm{mg} / \mathrm{L}$ chromate solution ( $\mathrm{pH} 4$ ) flowed into it. The tap column was opened to accommodate the solution that came out from the column. The exact procedure was repeated with different $\mathrm{pH} 5,6,7$, and 8. $\mathrm{Cr}(\mathrm{VI})$ infiltrate was analyzed by AAS. The flow rate variation also conducted in this study by varied flow rate at $0.05 ; 0.30 ; 0.70 ; 1.10$; and $1.50 \mathrm{~mL} / \mathrm{min}$ of $10 \mathrm{~mL}$ chromate ion $10 \mathrm{mg} / \mathrm{L}$ at optimum $\mathrm{pH}$. The remain $\mathrm{Cr}(\mathrm{VI})$ infiltrate was analyzed by AAS.

\section{Results and Discussion}

\subsection{Characterization of $\mathrm{QAMS}-\mathrm{Fe}_{3} \mathrm{O}_{4}$}

Fourier Transform-Infra Red (FT-IR) study of synthesized $\mathrm{Fe}_{3} \mathrm{O}_{4}$, AMS, QAMS, and QAMS- $\mathrm{Fe}_{3} \mathrm{O}_{4}$, was presented in Figure 1. For the sample of synthesized $\mathrm{Fe}_{3} \mathrm{O}_{4}$, the vibrational bands at around 890 and $520 \mathrm{~cm}^{-1}$ are characteristic of the $v(\mathrm{Fe}-0)$ lattice vibrations [28]. The QAMS- $\mathrm{Fe}_{3} \mathrm{O}_{4}$ sample shows a band at 788 and 1034 $\mathrm{cm}^{-1}$ corresponding to the stretching vibrations of $\mathrm{v}(\mathrm{Si}-$ $\mathrm{OH})$ and $\mathrm{v}(\mathrm{SiO}-\mathrm{Si})$, respectively [29]. The absorption band at $1636 \mathrm{~cm}^{-1}$ in the AMS, QAMS, and QAMS- $\mathrm{Fe}_{3} \mathrm{O}_{4}$ might be assigned to the $v(\mathrm{C}-\mathrm{N})$ stretching mode [30]. The broad absorption band at $3375 \mathrm{~cm}^{-1}$ was due to $v\left(\mathrm{O}_{-}\right.$ $\mathrm{H})$ stretching vibration, which corresponds to hydroxyl groups on the surface of iron oxide, and this band can be assigned to the adsorbed water molecules [31]. Additional bands were observed at $2939 \mathrm{~cm}^{-1}$ corresponding to the $-\mathrm{CH}_{3}$ and $-\mathrm{CH}_{2}-$ vibrations. The $v(\mathrm{C}-\mathrm{O})$ stretches were found at $2361 \mathrm{~cm}^{-1}$, which are typically very weak and convoluted by contamination of the background's $\mathrm{CO}_{2}$ stretching bands.

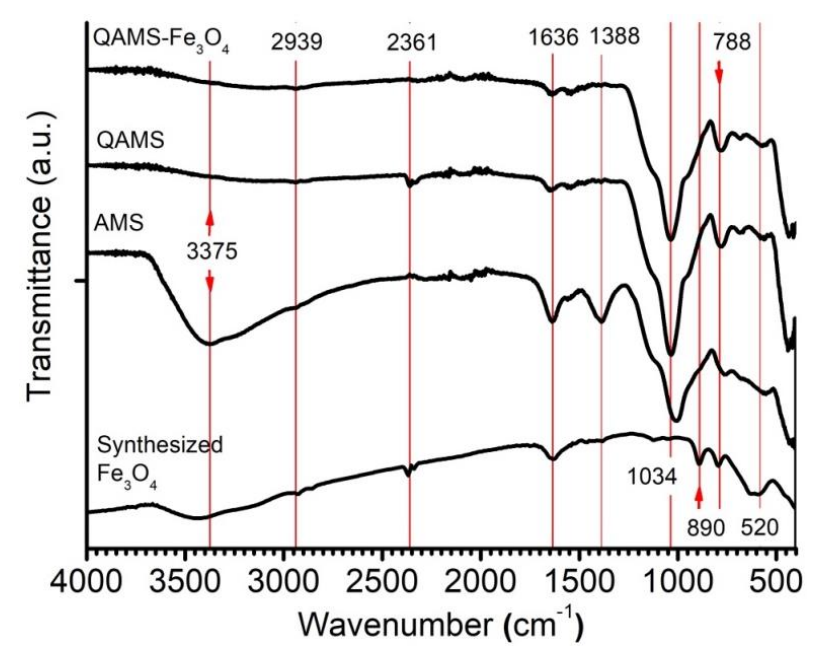

Figure 1. FTIR spectra of $\mathrm{QAMS}-\mathrm{Fe}_{3} \mathrm{O}_{4}, \mathrm{QAMS}, \mathrm{AMS}$, and Synthesized $\mathrm{Fe}_{3} \mathrm{O}_{4}$

The absorption band at $1388 \mathrm{~cm}^{-1}$ (bend vibration of $\mathrm{N}-\mathrm{H}$ from $-\mathrm{NH}_{2}$ group) in AMS indicated the AMS still has $-\mathrm{NH}_{2}$ group. However, QAMS and QAMS- $\mathrm{Fe}_{3} \mathrm{O}_{4}$ have not this absorbance that indicates there is no $-\mathrm{NH}_{2}$ group in QAMS and QAMS- $\mathrm{Fe}_{3} \mathrm{O}_{4}$. C-H stretching vibration from the methyl group emerged at $2939 \mathrm{~cm}^{-1}$ [32] was emerged only in QAMS, and QAMS- $\mathrm{Fe}_{3} \mathrm{O}_{4}$ indicates formed $-\mathrm{CH}_{3}$ at $\mathrm{QAMS}$ and $\mathrm{QAMS}-\mathrm{Fe}_{3} \mathrm{O}_{4}$. The differences of AMS and QAMS was disappearing absorbance at $1388 \mathrm{~cm}^{-1}$, and emerging absorbance at $2939 \mathrm{~cm}^{-1}$ in QAMS and QAMS- $\mathrm{Fe}_{3} \mathrm{O}_{4}$ indicated a transformation of $\mathrm{N}-\mathrm{H}$ from $-\mathrm{NH}_{2}$ group to $\left[-\mathrm{N}^{+}\left(\mathrm{CH}_{3}\right)_{3}\right]$ [11]. However, due to the similarity of the other functional groups of the QAMS and QAMS- $\mathrm{Fe}_{3} \mathrm{O}_{4}$, the infrared spectra were not conclusive about coating $\mathrm{Fe}_{3} \mathrm{O}_{4}$ on QMAS results were further supported by crystal, magnetic properties, morphology, and elemental chemical analysis.

Table 1 Experimental $d(\AA)$ spacing of synthesized $\mathrm{Fe}_{3} \mathrm{O}_{4}$ and QAMS $-\mathrm{Fe}_{3} \mathrm{O}_{4}$ from XRD pattern $d$ (exp) and $d$

(ASTM) spacing from ASTM data cards for iron oxide $\mathrm{Fe}_{3} \mathrm{O}_{4}$

\begin{tabular}{|c|c|c|c|c|}
\hline \multicolumn{2}{|c|}{$\mathrm{QAMS}-\mathrm{Fe}_{3} \mathrm{O}_{4}$} & \multicolumn{2}{|c|}{ Synthesized $\mathrm{Fe}_{3} \mathrm{O}_{4}$} & \multirow{2}{*}{$\frac{\mathrm{ASTM} \mathrm{Fe}_{3} \mathrm{O}_{4}}{d(\mathrm{ASTM})}$} \\
\hline $2 \theta\left({ }^{\circ}\right)$ & $d(\exp )$ & $2 \ominus\left(^{\circ}\right)$ & $d(\exp )$ & \\
\hline 30.26 & 2.954 & 30.15 & 2.972 & 2.967 \\
\hline 35.61 & 2.521 & 35.53 & 2.529 & 2.532 \\
\hline 43.12 & 2.082 & 43.12 & 2.082 & 2.099 \\
\hline 57.23 & 1.611 & 57.23 & 1.611 & 1.616 \\
\hline 62.90 & 1.478 & 62.90 & 1.478 & 1.485 \\
\hline
\end{tabular}




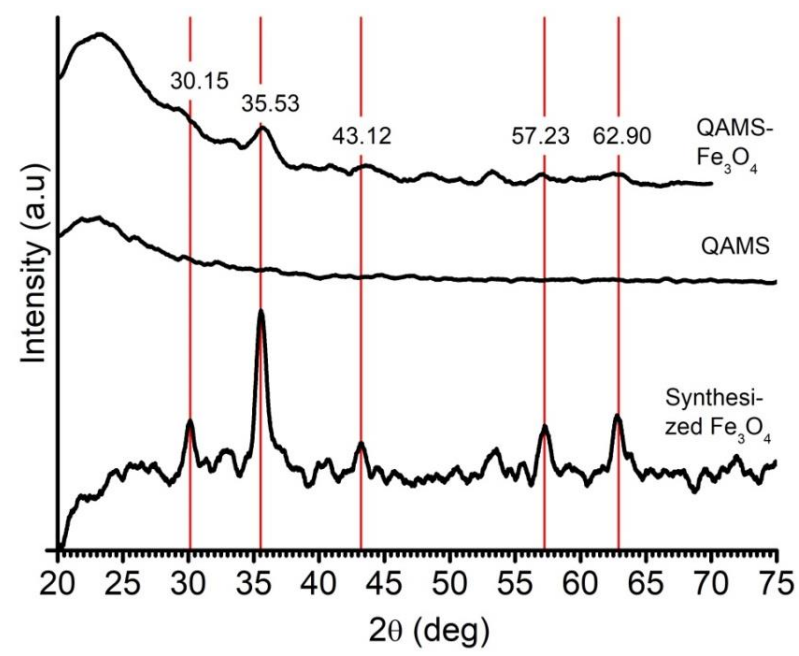

Figure 2. XRD pattern of $\mathrm{QAMS}-\mathrm{Fe}_{3} \mathrm{O}_{4}, \mathrm{QAMS}$, and synthesized magnetite, $\mathrm{Fe}_{3} \mathrm{O}_{4}$

X-ray diffractogram (XRD) analysis of AMS and QAMS shows that these all material are non-crystalline (amorphous), and $\mathrm{SiO}_{2}$ character emerges at $2 \theta=20-25^{\circ}$ (JCPDS No. 29-0085) [22, 25, 26, 27]. This condition was also reported by Della et al. [33] that there is no significant change in the diffractogram peak of the incinerating time of rice hulk ash to form silica gel. The diffractogram of QAMS- $\mathrm{Fe}_{3} \mathrm{O}_{4}, \mathrm{QAMS}$, and AMS was presented in Figure 2. From the synthesized $\mathrm{Fe}_{3} \mathrm{O}_{4}$ diffractogram can be seen that there are peaks which indicate the iron oxide as $\mathrm{Fe}_{3} \mathrm{O}_{4}$ crystal which identified at $2 \theta=30.15^{\circ}(220) ; 35.53^{\circ}(311) ; 43.12^{\circ}(400) ; 57.22^{\circ}$ (511), and $62.90^{\circ}$ (440) (JCPDS No. 00-033-0664) [29, 30]. Based on the matching of $d$ (exp) with $d$ (ASTM) spacing from ASTM data cards for iron oxide $\mathrm{Fe}_{3} \mathrm{O}_{4}$ [34] (Table 1), it can be concluded that the iron oxide particles are mainly composed of the inverse cubic spinel structure $[30,32]$. Emerging peak at $2 \theta=30.15^{\circ} ; 35.53^{\circ}$; $43.12^{\circ} ; 57.22^{\circ}$, and $62.90^{\circ}$ on QAMS- $\mathrm{Fe}_{3} \mathrm{O}_{4}$ demonstrated the success of the $\mathrm{Fe}_{3} \mathrm{O}_{4}$ coating with QAMS (Figure 2).

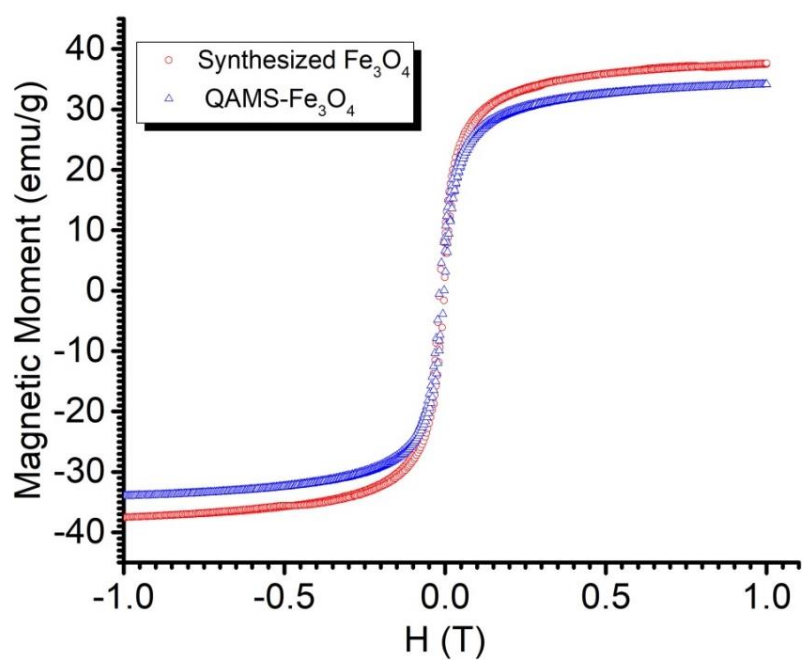

Figure 3. Hysteresis loops of synthesized $\mathrm{Fe}_{3} \mathrm{O}_{4}$ and $\mathrm{QAMS}-\mathrm{Fe}_{3} \mathrm{O}_{4}$ at room temperature.

The core/shell QAMS- $\mathrm{Fe}_{3} \mathrm{O}_{4}$ material must possess sufficient magnetic and paramagnetic properties for practical application. The hysteresis loops of synthesized
$\mathrm{Fe}_{3} \mathrm{O}_{4}$ and QAMS- $\mathrm{Fe}_{3} \mathrm{O}_{4}$ are shown in Figure 3. Both of them showed the paramagnetic character. The saturation magnetization of $\mathrm{Fe}_{3} \mathrm{O}_{4}$ by reduction coprecipitation method was $37.6 \mathrm{emu} / \mathrm{g}$, which agreed with the reported value $[32,35,36]$. The reduction of a saturation magnetization value was expected due to the QAMS coat [37]. The coating of the $\mathrm{Fe}_{3} \mathrm{O}_{4}$ with QAMS only caused a decrease of a further $9.3 \%$, giving a final value of $34.1 \mathrm{emu} / \mathrm{g}$, making it still very strongly responsive to an external magnetic field. The magnetically separated QAMS $-\mathrm{Fe}_{3} \mathrm{O}_{4}$ was not permanently magnetized and can be re-dispersed without any signs of re-aggregation when the external magnetic field is removed.

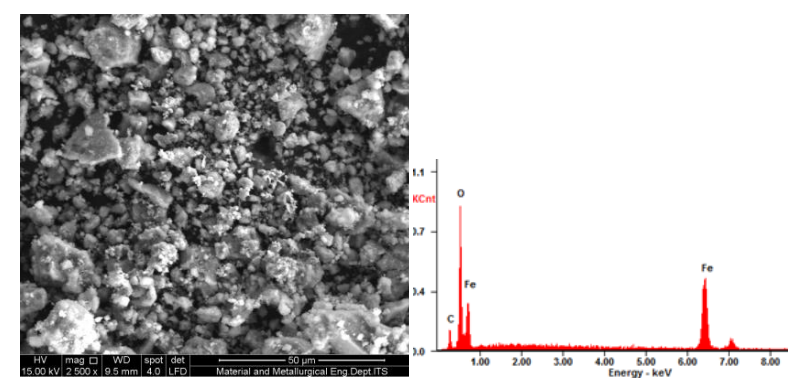

(a)

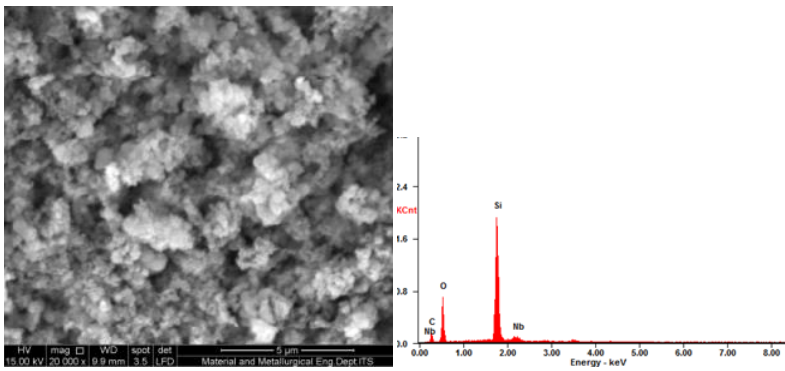

(b)
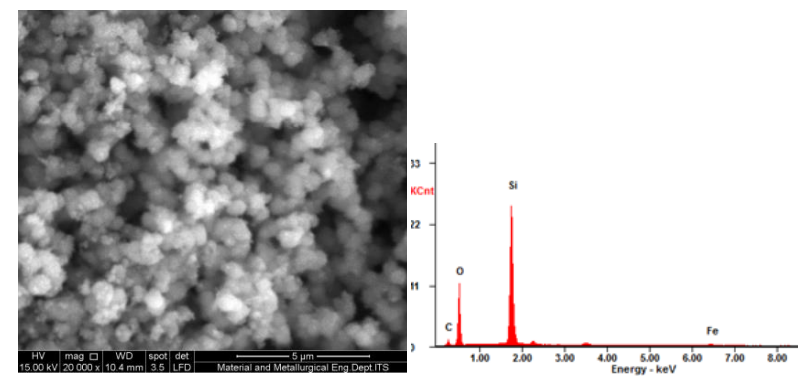

(c)

Figure 4. Morphological image (2500x magnitude) and elemental composition by EDX of (a) $\mathrm{Fe}_{3} \mathrm{O}_{4}$, (b) QAMS, and (c) QAMS- $\mathrm{Fe}_{3} \mathrm{O}_{4}$

The surface morphology by SEM-EDX analysis before and after the coating of QAMS and QAMS- $\mathrm{Fe}_{3} \mathrm{O}_{4}$ shows that the surface morphology of QAMS- $\mathrm{Fe}_{3} \mathrm{O}_{4}$ more homogenous topological spherical form with an average particle size $0.006 \mu \mathrm{m}$ (from image J) than QAMS (Figure 4). From EDX data, QAMS only consists of elements $\mathrm{Si}$, $\mathrm{O}, \mathrm{C}$, and $\mathrm{N}$. However, in QAMS- $\mathrm{Fe}_{3} \mathrm{O}_{4}$, there was $\mathrm{Fe}$ (1.77\%). Compared to $\mathrm{Fe}_{3} \mathrm{O}_{4}$ (Table 2), the Fe percentage in $\mathrm{QAMS}-\mathrm{Fe}_{3} \mathrm{O}_{4}(76.10)$ was relatively low. 
Table 2. The elemental analysis by EDX of QAMS, synthesized $\mathrm{Fe}_{3} \mathrm{O}_{4}$, and QAMS- $\mathrm{Fe}_{3} \mathrm{O}_{4}$

\begin{tabular}{|c|c|c|c|c|c|c|}
\hline \multirow{2}{*}{ Elements } & \multicolumn{2}{|c|}{ QAMS } & \multicolumn{2}{|c|}{$\begin{array}{c}\text { Synthesized } \\
\mathrm{Fe}_{3} \mathrm{O}_{4}\end{array}$} & \multicolumn{2}{|c|}{$\mathrm{QAMS}-\mathrm{Fe}_{3} \mathrm{O}_{4}$} \\
\hline & $\begin{array}{c}\text { Mass } \\
(\%)\end{array}$ & $\begin{array}{c}\text { Atom } \\
(\%)\end{array}$ & $\begin{array}{c}\text { Mass } \\
(\%)\end{array}$ & $\begin{array}{c}\text { Atom } \\
(\%)\end{array}$ & $\begin{array}{c}\text { Mass } \\
(\%)\end{array}$ & $\begin{array}{c}\text { Atom } \\
(\%)\end{array}$ \\
\hline $\mathrm{C}$ & 12.16 & 20.64 & 4.17 & 11.79 & 10.54 & 11.45 \\
\hline 0 & 32.00 & 41.67 & 19.73 & 42.42 & 31.67 & 45.22 \\
\hline $\mathrm{Si}$ & 49.28 & 35.78 & - & - & 48.81 & 39.54 \\
\hline $\mathrm{Fe}$ & - & - & 76.10 & 46.31 & 4.70 & 1.77 \\
\hline $\mathrm{N}$ & 5.27 & 1.16 & - & - & 4.28 & 2.02 \\
\hline I & 1.29 & 0.23 & - & - & - & - \\
\hline
\end{tabular}

RHA was generated from incinerating rice husk at $700{ }^{\circ} \mathrm{C}$, as represented in equation reaction (1). The destruction process of RHA by $\mathrm{NaOH}$ would dissolve silica to generate red filtrate $\mathrm{Na}$-Silica (eq. reaction (2)). Na-Silica has a very high solubility in $\mathrm{pH}>10$. To separate it, $\mathrm{HCl}$ added into $\mathrm{pH}$ neutral to isolated $\mathrm{Na}-$ Silica (condensation, eq. reaction (3)) [38]. The mechanism reaction for AMS formation was silane from 3-APTMS as a coupling agent release the amine functional group and then replaced by the silanol functional group. The amine group binds to the silica surface through a mechanism of electrophilic proton substitution reaction [39]. The AMS Methylation process is believed to be a nucleophile substitution $\left(\mathrm{SN}^{2}\right)$ reaction by three carbon atoms with a methyl group being attacked by the nucleophile, an amine group replacing two $\mathrm{H}$ atoms with three methyl group generate QAMS with a naturally positive charge [26]. The proposed mechanism of QAMS formation from AMS is based on the reaction equation by de Campos et al. [26] presented in Figure 1. The primary evidence of QAMS formation was the FTIR spectra, i.e., disappearing absorbance at $1388 \mathrm{~cm}^{-1}$, and emerging absorbance at $2939 \mathrm{~cm}^{-1}$ in QAMS indicated a transformation of $\mathrm{N}-\mathrm{H}$ from $-\mathrm{NH}_{2}$ group to $\left[-\mathrm{N}+\left(\mathrm{CH}_{3}\right)_{3}\right]$ (Figure 1) and the existence of I (iodide) as the counter anions of QAMS (EDX data, Table 2).

Substance $\mathrm{C}, \mathrm{H}$, and $\mathrm{Si}(\mathrm{s})+\mathrm{O}_{2}(\mathrm{~g}) \rightarrow \mathrm{CO}_{2}(\mathrm{~g})+\mathrm{H}_{2} \mathrm{O}(\mathrm{l})+$ $\mathrm{SiO}_{2}(\mathrm{~s})$

$\mathrm{SiO}_{2}(\mathrm{~s})+2 \mathrm{NaOH}(\mathrm{aq}) \rightarrow \mathrm{Na}_{2} \mathrm{SiO}_{3}(\mathrm{aq})+\mathrm{H}_{2} \mathrm{O}(\mathrm{l})$

$\mathrm{Na}_{2} \mathrm{SiO}_{3}(\mathrm{aq})+\mathrm{H}_{2} \mathrm{O}(\mathrm{l})+2 \mathrm{HCl}(\mathrm{aq}) \rightarrow \mathrm{Si}(\mathrm{OH})_{4}(\mathrm{~s})+\mathrm{NaCl}$ (aq)

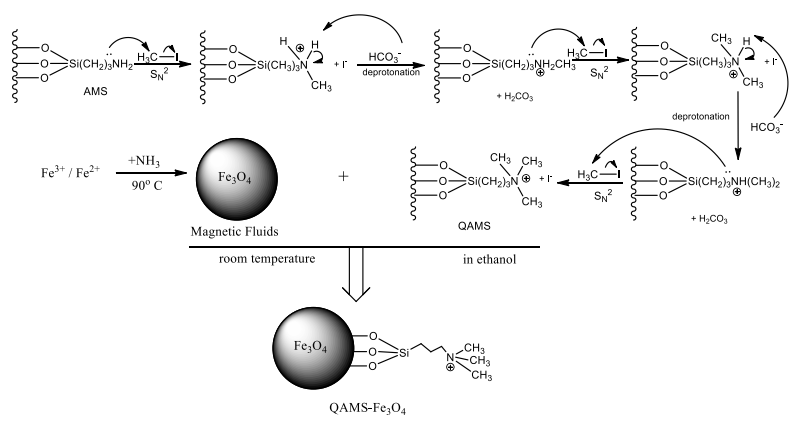

Figure 5 The proposed mechanism of QAMS formation from AMS and the proposed structural model of QAMS$\mathrm{Fe}_{3} \mathrm{O}_{4}$.
Coating magnetite by QAMS occurs in $\mathrm{pH}$ neutral to prevent magnetite damage in acid and QAMS in alkaline [21]. The physical appearance of $\mathrm{QAMS}-\mathrm{Fe}_{3} \mathrm{O}_{4}$ (dark grey) was the coherence of its constituent magnetite (black) and QAMS (pale white). Based on the characterization of XRD (QAMS- $\mathrm{Fe}_{3} \mathrm{O}_{4}$ have very similar position $2 \theta$ and $\mathrm{d}$ spacing with the standard d spacing), VSM (QAMS- $\mathrm{Fe}_{3} \mathrm{O}_{4}$ have a magnetic moment: $34.1 \mathrm{emu} / \mathrm{g}$ ), SEM (QAMS$\mathrm{Fe}_{3} \mathrm{O}_{4}$ have a spherical shape), and the literature with similar methods $[13,29,40]$, it can be deduced that the $\mathrm{Fe}_{3} \mathrm{O}_{4}$ was core shelled by QAMS (Figure 5).

\subsection{Stability Test of $\mathrm{QAMS}-\mathrm{Fe}_{3} \mathrm{O}_{4}$}

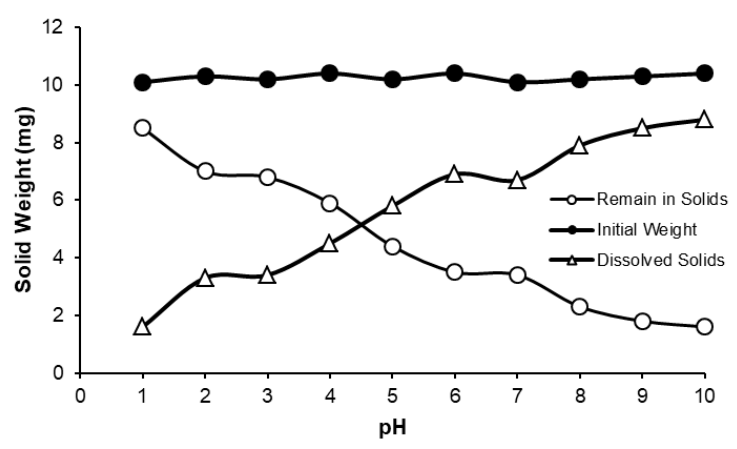

Figure 6. Stability of QAMS- $\mathrm{Fe}_{3} \mathrm{O}_{4}$ in various alkaline/acidic medium

The stability of the adsorbent was a vital parameter to know how much $\mathrm{Fe}_{3} \mathrm{O}_{4}$ reinforces the SMQA. The higher the acidity, the more stable the QAMS- $\mathrm{Fe}_{3} \mathrm{O}_{4}$. By increasing $\mathrm{pH}$, the more adsorbent dissolved (Figure 6). This result indicates that the character of adsorbent is still dominated by SMQA stable in the acidic medium [11]. The role of $\mathrm{Fe}_{3} \mathrm{O}_{4}$ that should stabilize QAMS in an alkaline medium was not significantly seen yet. This result will be used as a reference for improving the coating method $\mathrm{Fe}_{3} \mathrm{O}_{4}$ on QMAS in future research.

\subsection{Chromate Anions Adsorption Study by SPA}

In $\mathrm{pH}$ variation medium (flow rate $0.7 \mathrm{~mL} / \mathrm{min}$ ), the highest sorbed of $\mathrm{Cr}(\mathrm{VI})$ was at $\mathrm{pH} 6(99 \%)$, and the smallest remaining concentration is at $\mathrm{pH} 8(76 \%)$. Conversion sorption percentage to sorbed chromate anions in this condition was $9.99 \mathrm{mg} / \mathrm{g}$ adsorbent. It was estimated that the capacity of $\mathrm{QAMS}-\mathrm{Fe}_{3} \mathrm{O}_{4}$ higher than that value. The capacity of the adsorbent has an optimum value at a flow rate of $1.00 \mathrm{~mL} \mathrm{~min}{ }^{-1}$. The sorbed chromate anions estimated continues to decrease, along with increasing $\mathrm{pH}$ (Figure 7). Previously, treated rice husk for $\mathrm{Cr}(\mathrm{VI})$ removal was $71.0 \%$ and $76.5 \%$ respectively for dilute solutions at $20 \mathrm{~g} \mathrm{~L}^{-1}$ adsorbent dose [41].

Recently, a similar adsorbent was reported by Huang et al. [42], graphene oxide-mesoporous silica (GO-MS) nanosheets with 3-(2-amino ethyl amino) propyl trimethoxysilane as the functional monomer showed that capacity of its adsorbent was $438.1 \mathrm{mg} / \mathrm{g}$ adsorbent to adsorb $\mathrm{Cr}(\mathrm{VI})$. From the result in Figure 7 , the optimum $\mathrm{pH}$ occurs at $\mathrm{pH} \mathrm{6,} \mathrm{where} \mathrm{the} \mathrm{chromate}$ anions maximum sorbed. Adsorption at $\mathrm{pH} 6$ was also in accordance with the diagram of the relationship between 
ion strength to $\mathrm{pH}$ (Pourbaix diagram) where $\mathrm{Cr}(\mathrm{VI})$ was in chromate anion form [43]. Optimum adsorption of chromate anions occurs at a flow rate of $0.7 \mathrm{~mL} / \mathrm{min}$ $(90.5 \%)$. This result proves that the more contact chromate solution, the more it sorbed to the adsorbent. The sorbed $\mathrm{Cr}(\mathrm{VI})$ on QAMS-Fe304 as a function of $\mathrm{pH}$ and flow rate can be seen in Figure 7.
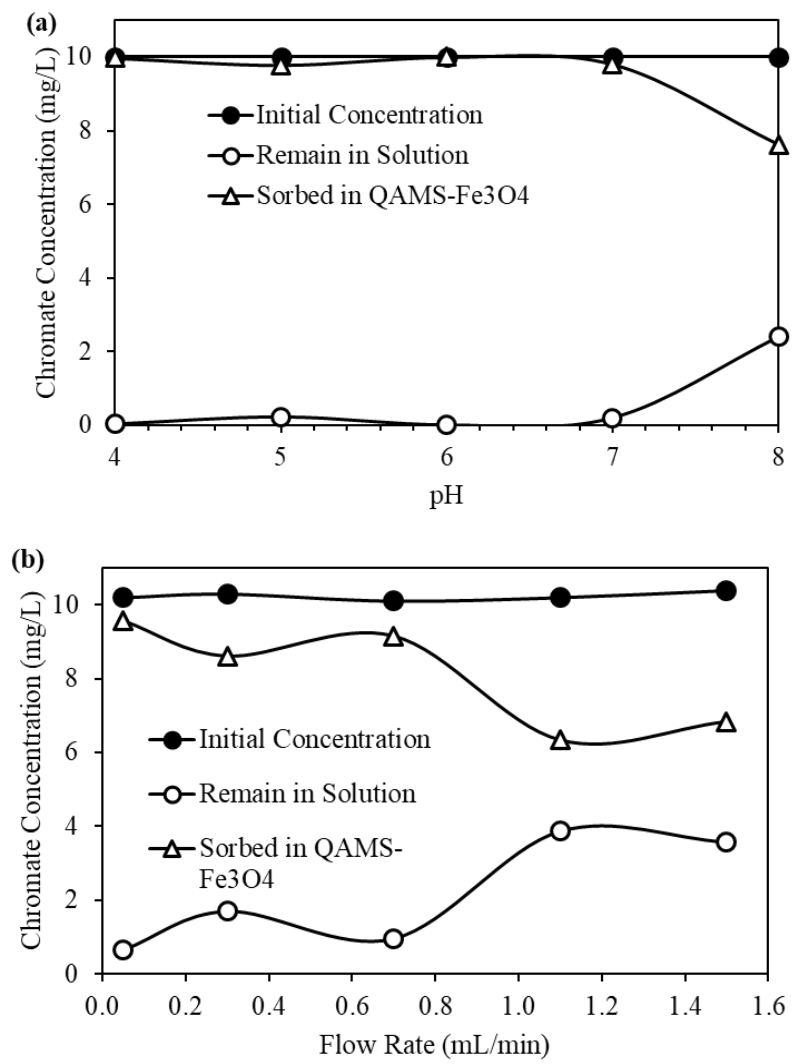

Figure 7. $\mathrm{Cr}(\mathrm{VI})$ sorbed on $\mathrm{QAMS}-\mathrm{Fe}_{3} \mathrm{O}_{4}$ as function of (a) $\mathrm{pH}$ at flow rate $0.7 \mathrm{~mL} / \mathrm{min}$ and (b) flow rate.

\section{Conclusions}

It was remarkable research of pre-study in coating $\mathrm{Fe}_{3} \mathrm{O}_{4}$ on QAMS. Instrumental characterization of QMAS$\mathrm{Fe}_{3} \mathrm{O}_{4}$ by FT-IR (disappearing absorbance at $1388 \mathrm{~cm}^{-1}$, and emerging absorbance at $2939 \mathrm{~cm}^{-1}$ in QAMS and QAMS- $\mathrm{Fe}_{3} \mathrm{O}_{4}$ indicated a transformation of $\mathrm{N}-\mathrm{H}$ from $\mathrm{NH}_{2}$ group to $\left.\left[-\mathrm{N}^{+}\left(\mathrm{CH}_{3}\right)_{3}\right]\right)$. XRD $\left(2 \theta=30.15^{\circ}, 35.53^{\circ}\right.$, $43.12^{\circ}, 57.22^{\circ}$, and $62.90^{\circ}$ (JCPDS No. 00-033-0664) fathomed as a characteristic peak of magnetite). SEMEDX (the homogenous topological spherical form with average particle size $0.006 \mu \mathrm{m}$ that dominated by $\mathrm{Si}$ element $(52.81 \%$ ), and VSM (magnetic moment value = $34.1 \mathrm{emu} / \mathrm{g}$ ) indicate the $\mathrm{Fe}_{3} \mathrm{O}_{4}$ convincingly coated by QAMS. Although it is necessary to improve the method to increase the binding of $\mathrm{Fe}_{3} \mathrm{O}_{4}$ to QAMS because QMAS$\mathrm{Fe}_{3} \mathrm{O}_{4}$ is still not stable in an alkaline medium, the optimal $\mathrm{pH}$ is obtained in the range of $4-7$, with more than $90 \%$ of the chromate ions adsorbed. This indicates that the synthesized adsorbent for chromate anion adsorption by the SPA method was successful. Even the SPA method is more suitable for adsorbent that is difficult to separate after the adsorption process. The SPA could also be applied in the very vast adsorbent and easy handling of desorption due to the adsorbent reusability.

\section{Acknowledgment}

The authors acknowledge LPPM Universitas Jambi for funded this research through PNBP LPPM Universitas Jambi by contract number 453/UN21.18/PG/SPK/2020.

\section{References}

[1] Try Susanti, Wiji Utami, Hidayat Hidayat, The negative impact of illegal gold mining on the environmental sector in Batang Asai, Jambi, Sustinere: Journal of Environment and Sustainability, 2, 3, (2018), 128-143

https://doi.org/10.22515/sustinere.jes.v2i3.43

[2] Zeeshanur Rahman, Ved Pal Singh, The relative impact of toxic heavy metals (THMs) (arsenic (As), cadmium (Cd), chromium $(\mathrm{Cr})(\mathrm{VI})$, mercury $(\mathrm{Hg})$, and lead $(\mathrm{Pb})$ ) on the total environment: an overview, Environmental Monitoring and Assessment, 191, 7, (2019), 419 https://doi.org/10.1007/s10661-019-7528-7

[3] Vhahangwele Masindi, Khathutshelo L. Muedi, Environmental contamination by heavy metals, in: Heavy metals, IntechOpen, 2018, https://doi.org/10.5772/intechopen.76082

[4] Jisuan Tan, Yiheng Song, Xiaohua Huang, Li Zhou, Facile Functionalization of Natural Peach Gum Polysaccharide with Multiple Amine Groups for Highly Efficient Removal of Toxic Hexavalent Chromium ( $\mathrm{Cr}(\mathrm{VI}))$ Ions from Water, ACS Omega, 3, 12, (2018), 17309-17318 https://doi.org/10.1021/acsomega.8b02599

[5] Steffita Rahayuning Purbandini, Abdul Haris, Effect of $\mathrm{ZnO}$ Dopant on $\mathrm{TiO}_{2}$ on Simultaneous Decrease of Phenol, Pb (II) and COD using Photocatalysis Method, Jurnal Kimia Sains dan Aplikasi, 21, 1, (2018), 34-38 https://doi.org/10.14710/jksa.17.3.86-89

[6] Rumpa Saha, Rumki Nandi, Bidyut Saha, Sources and toxicity of hexavalent chromium, Journal of Coordination Chemistry, 64, 10, (2011), 1782-1806 https://doi.org/10.1080/00958972.2011.583646

[7] Mohammad Hadi Dehghani, Daryoush Sanaei, Imran Ali, Amit Bhatnagar, Removal of chromium(VI) from aqueous solution using treated waste newspaper as a low-cost adsorbent: Kinetic modeling and isotherm studies, Journal of Molecular Liquids, 215, (2016), 671-679 https://doi.org/10.1016/j.molliq.2015.12.057

[8] Yuanji Shi, Tao Zhang, Hongqiang Ren, Andrea Kruse, Ruofan Cui, Polyethylene imine modified hydrochar adsorption for chromium (VI) and nickel (II) removal from aqueous solution, Bioresource Technology, 247, (2018), 370-379 https://doi.org/10.1016/j.biortech.2017.09.107

[9] N. Soltani, A. Bahrami, M. I. Pech-Canul, L. A. González, Review on the physicochemical treatments of rice husk for production of advanced materials, Chemical Engineering Journal, 264, (2015), 899-935 https://doi.org/10.1016/j.cej.2014.11.056

[10] Siti Sulastri, Nuryono Nuryono, Indriana Kartini, Eko Sri Kunarti, Adsorption of $\mathrm{Ca}(\mathrm{II}), \mathrm{Pb}$ (II) and $\mathrm{Ag}$ (I) on Sulfonato-Silica Hybrid Prepared from Rice Hull Ash, Indonesian Journal of Chemistry, 11, 3, (2011), 273-278 https://doi.org/10.22146/ijc.21392 
[11] Ngatijo Ngatijo, Rahmat Basuki, Nuryono Nuryono, Bambang Rusdiarso, Comparison of Au (III) Sorption on Amine-Modified Silica (AMS) and Quaternary Amine-Modified Silica (QAMS): A Thermodynamic and Kinetics Study, Indonesian Journal of Chemistry, 19, 2, (2018), 337-346

https://doi.org/10.22146/ijc.33758

[12] Ngatijo, Rahmat Basuki, Bambang Rusdiarso, Nuryono, Sorption-desorption profile of $\mathrm{Au}(\mathrm{III})$ onto silica modified quaternary amines (SMQA) in gold mining effluent, Journal of Environmental Chemical Engineering, 8, 3, (2020), 103747 https://doi.org/10.1016/j.jece.2020.103747

[13] Wei Yao, Pinhua Rao, Yongtao Du, Wenqi Zhang, Tongzhou Liu, Synthesis of magnetic silica with quaternary ammonium salt and its application for chromium(VI) removal, Desalination and Water Treatment, 55, 1, (2015), 173-182 https://doi.org/10.1080/19443994.2014.911115

[14] Fauziatul Fajaroh, Heru Setyawan, Adrian Nur, I. Wuled Lenggoro, Thermal stability of silica-coated magnetite nanoparticles prepared by an electrochemical method, Advanced Powder Technology, 24, 2, (2013), 507-511 https://doi.org/10.1016/j.apt.2012.09.008

[15] Shik Chi Tsang, Chih Hao Yu, Xin Gao, Kin Tam, Silica-Encapsulated Nanomagnetic Particle as a New Recoverable Biocatalyst Carrier, The Journal of Physical Chemistry B, 110, 34, (2006), 16914-16922 https://doi.org/10.1021/jp062275s

[16] Marcos E. Peralta, Santiago Ocampo, Israel G. Funes, Florencia Onaga Medina, María E. Parolo, Luciano Carlos, Nanomaterials with Tailored Magnetic Properties as Adsorbents of Organic Pollutants from Wastewaters, Inorganics, 8, 4, (2020), https://doi.org/10.3390/inorganics 8040024

[17] Ying-Sing Li, Jeffrey S. Church, Andrea L. Woodhead, Filsun Moussa, Preparation and characterization of silica coated iron oxide magnetic nano-particles, Spectrochimica Acta Part A: Molecular and Biomolecular Spectroscopy, 76, 5, (2010), 484-489 https://doi.org/10.1016/j.saa.2010.04.004

[18] R. V. Ferreira, I. L. S. Pereira, L. C. D. Cavalcante, L. F. Gamarra, S. M. Carneiro, E. Amaro, J. D. Fabris, R. Z. Domingues, A. L. Andrade, Synthesis and characterization of silica-coated nanoparticles of magnetite, Hyperfine Interactions, 195, 1, (2010), 265274 https://doi.org/10.1007/s10751-009-0128-0

[19] Krzysztof Cendrowski, Pawel Sikora, Beata Zielinska, Elzbieta Horszczaruk, Ewa Mijowska, Chemical and thermal stability of core-shelled magnetite nanoparticles and solid silica, Applied Surface Science, 407, (2017), 391-397

https://doi.org/10.1016/j.apsusc.2017.02.118

[20]Tehreema Nawaz, Sonia Zulfiqar, Muhammad Ilyas Sarwar, Mudassir Iqbal, Synthesis of diglycolic acid functionalized core-shell silica coated $\mathrm{Fe}_{3} \mathrm{O}_{4}$ nanomaterials for magnetic extraction of $\mathrm{Pb}$ (II) and $\mathrm{Cr}(\mathrm{VI})$ ions, Scientific Reports, 10, 1, (2020), 10076 https://doi.org/10.1038/s41598-020-67168-2

[21] Nuryono Nuryono, Nur Mutia Rosiati, Bambang Rusdiarso, Satya Candra Wibawa Sakti, Shunitz Tanaka, Coating of magnetite with mercapto modified rice hull ash silica in a one-pot process,
SpringerPlus, 3, 1, (2014), 515

https://doi.org/10.1186/2193-1801-3-515

[22]Rahmat Basuki, Ngatijo Ngatijo, Sri Juari Santosa, Bambang Rusdiarso, Comparison the New Kinetics Equation of Non-competitive Sorption Cd (II) and Zn (II) onto Green Sorbent Horse Dung Humic Acid (HD-HA), Bulletin of Chemical Reaction Engineering \& Catalysis, 13, 3, (2018), 475-488

https://doi.org/10.9767/bcrec.13.3.1774.475-488

[23] Lisa Aprilia Indriyani, Zulhan Arif, Roza Linda, Henny Purwaningsih, Mohamad Rafi, Pengoptimuman Kondisi Adsorpsi Cd (II) oleh Adsorben Berbasis Silika Termodifikasi Glisina Menggunakan Central Composite Design, Jurnal Kimia Sains dan Aplikasi, 22, 5, (2019), 184-191 https://doi.org/10.14710/jksa.22.5.184-191

[24]Yi-Wei Wu, Jing Zhang, Jun-Feng Liu, Lin Chen, Zhen-Li Deng, Mu-Xian Han, Xiao-Shu Wei, Ai-Min $\mathrm{Yu}$, Hai-Li Zhang, Fe3O4@ZrO2 nanoparticles magnetic solid phase extraction coupled with flame atomic absorption spectrometry for chromium(III) speciation in environmental and biological samples, Applied Surface Science, 258, 18, (2012), 6772-6776 https://doi.org/10.1016/j.apsusc.2012.03.057

[25]Qian Liu, Jianbo Shi, Jianteng Sun, Thanh Wang, Lixi Zeng, Guibin Jiang, Graphene and graphene oxide sheets supported on silica as versatile and highperformance adsorbents for solid-phase extraction, Angewandte Chemie, 123, 26, (2011), 6035-6039 https://doi.org/10.1002/ange.201007138

[26]Elvio A. de Campos, Antonio A. da Silva Alfaya, Rosilene T. Ferrari, Creusa Maieru M. Costa, Quaternary Ammonium Salts Immobilized on Silica Gel: Exchange Properties and Application as Potentiometric Sensor for Perchlorate Ions, Journal of Colloid and Interface Science, 240, 1, (2001), 97-104 https://doi.org/10.1006/jcis.2001.7649

[27]Dong Yang, Jianhua Hu, Shoukuan Fu, Controlled Synthesis of Magnetite-Silica Nanocomposites via a Seeded Sol-Gel Approach, The Journal of Physical Chemistry C, 113, 18, (2009), 7646-7651 https://doi.org/10.1021/jp900868d

[28]Ian J. Bruce, James Taylor, Michael Todd, Martin J. Davies, Enrico Borioni, Claudio Sangregorio, Tapas Sen, Synthesis, characterisation and application of silica-magnetite nanocomposites, Journal of Magnetism and Magnetic Materials, 284, (2004), 145160 https://doi.org/10.1016/j.jmmm.2004.06.032

[29]Penka I. Girginova, Ana L. Daniel-da-Silva, Cláudia B. Lopes, Paula Figueira, Marta Otero, Vítor S. Amaral, Eduarda Pereira, Tito Trindade, Silica coated magnetite particles for magnetic removal of $\mathrm{Hg}^{2+}$ from water, Journal of Colloid and Interface Science, 345, 2, (2010), 234-240 https://doi.org/10.1016/j.jcis.2010.01.087

[30]Aránzazu del Campo, Tapas Sen, Jean-Paul Lellouche, Ian J. Bruce, Multifunctional magnetite and silica-magnetite nanoparticles: Synthesis, surface activation and applications in life sciences, Journal of Magnetism and Magnetic Materials, 293, 1, (2005), 33-40 https://doi.org/10.1016/j.jmmm.2005.01.040

[31] Othman Hakami, Yue Zhang, Charles J. Banks, Thiol-functionalised mesoporous silica-coated magnetite nanoparticles for high efficiency removal 
and recovery of $\mathrm{Hg}$ from water, Water Research, 46, 12 , (2012), 3913-3922

https://doi.org/10.1016/j.watres.2012.04.032

[32] Pradip B. Sarawade, Jong-Kil Kim, Askwar Hilonga, Dang Viet Quang, Sun Jeong Jeon, Hee Taik Kim, Synthesis of sodium silicate-based hydrophilic silica aerogel beads with superior properties: Effect of heat-treatment, Journal of Non-Crystalline Solids, 357, 10, (2011), 2156-2162

https://doi.org/10.1016/j.jnoncrysol.2011.02.022

[33] V. P. Della, I. Kühn, D. Hotza, Rice husk ash as an alternate source for active silica production, Materials Letters, 57, 4, (2002), 818-821 https://doi.org/10.1016/S0167-577X(02)00879-0

[34]Yong-Hui Deng, Chang-Chun Wang, Jian-Hua Hu, $\mathrm{Wu}-\mathrm{Li}$ Yang, Shou-Kuan $\mathrm{Fu}$, Investigation of formation of silica-coated magnetite nanoparticles via sol-gel approach, Colloids and Surfaces A: Physicochemical and Engineering Aspects, 262, 1, (2005), 87-93

https://doi.org/10.1016/j.colsurfa.2005.04.009

[35]Uruthira Kalapathy, Andrew Proctor, John Shultz, Silicate Thermal Insulation Material from Rice Hull Ash, Industrial \& Engineering Chemistry Research, 42, 1, (2003), 46-49 https://doi.org/10.1021/ie0203227

[36]Silviana Silviana, Bakti Jos, Herry Santosa, Siswo Sumardiono, Statistical Approach for Water Glass Precursor Preparation from Bamboo Leaf Silica, Jurnal Kimia Sains dan Aplikasi, 22, 2, (2019), 52-57 https://doi.org/10.14710/jksa.22.2.52-57

[37] Jinshui Liu, Xuezhong Du, Fast removal of aqueous $\mathrm{Hg}$ (II) with quaternary ammonium-functionalized magnetic mesoporous silica and silica regeneration, Journal of Materials Chemistry, 21, 19, (2011), 69816987 http://dx.doi.org/10.1039/C1JM10111K

[38]Lazar Kopanja, Irena Milosevic, Matjaz Panjan, Vesna Damnjanovic, Marin Tadic, Sol-gel combustion synthesis, particle shape analysis and magnetic properties of hematite $\left(\alpha-\mathrm{Fe}_{2} \mathrm{O}_{3}\right)$ nanoparticles embedded in an amorphous silica matrix, Applied Surface Science, 362, (2016), 380-386 https://doi.org/10.1016/j.apsusc.2015.11.238

[39]Marwa Elkady, Hassan Shokry Hassan, Aly Hashim, Immobilization of Magnetic Nanoparticles onto Amine-Modified Nano-Silica Gel for Copper Ions Remediation, Materials, 9, 6, (2016), 460

https://doi.org/10.3390/ma9060460

[40] Tayyebeh Madrakian, Abbas Afkhami, Mohammad Ali Zolfigol, Mazaher Ahmadi, Nadia Koukabi, Application of Modified Silica Coated Magnetite Nanoparticles for Removal of Iodine from Water Samples, Nano-Micro Letters, 4, 1, (2012), 57-63 https://doi.org/10.1007/BF03353693

[41] Manjeet Bansal, Umesh Garg, Diwan Singh, V. K. Garg, Removal of $\mathrm{Cr}(\mathrm{VI})$ from aqueous solutions using pre-consumer processing agricultural waste: A case study of rice husk, Journal of Hazardous Materials, 162, 1, (2009), 312-320 https://doi.org/10.1016/j.jhazmat.2008.05.037

[42]Renfeng Huang, Xiaoguo Ma, Xin Li, Lihui Guo, Xiaowen Xie, Menyuan Zhang, Jing Li, A novel ionimprinted polymer based on graphene oxidemesoporous silica nanosheet for fast and efficient removal of chromium (VI) from aqueous solution,
Journal of Colloid and Interface Science, 514, (2018), 544-553 https://doi.org/10.1016/j.jcis.2017.12.065

[43]Hai-xia You, Hong-bin Xu, Yi Zhang, Shi-li Zheng, Yi-ying Gao, Potential- $\mathrm{pH}$ diagrams of $\mathrm{Cr}-\mathrm{H}_{2} \mathrm{O}$ system at elevated temperatures, Transactions of Nonferrous Metals Society of China, 20, (2010), s26-s31 https://doi.org/10.1016/S1003-6326(10)60006-4 